\title{
Extracorporeal membrane oxygenation for COVID-19: a systematic review and meta-analysis
}

Kollengode Ramanathan ${ }^{1,2^{*}+}$ (], Kiran Shekar ${ }^{3,4,5,6+}$, Ryan Ruiyang Ling ${ }^{1}$, Ryan P. Barbaro ${ }^{7,8}$, Suei Nee Wong ${ }^{1}$, Chuen Seng Tan ${ }^{1,9}$, Bram Rochwerg ${ }^{10,11}$, Shannon M. Fernando ${ }^{12}$, Shinhiro Takeda ${ }^{13}$, Graeme MacLaren ${ }^{1,2}$, Eddy Fan ${ }^{14}$ and Daniel Brodie ${ }^{15,16}$

\begin{abstract}
Background: There are several reports of extracorporeal membrane oxygenation (ECMO) use in patients with coronavirus disease 2019 (COVID-19) who develop severe acute respiratory distress syndrome (ARDS). We conducted a systematic review and meta-analysis to guide clinical decision-making and future research.

Methods: We searched MEDLINE, Embase, Cochrane and Scopus databases from 1 December 2019 to 10 January 2021 for observational studies or randomised clinical trials examining ECMO in adults with COVID-19 ARDS. We performed random-effects meta-analyses and meta-regression, assessed risk of bias using the Joanna Briggs Institute checklist and rated the certainty of evidence using the GRADE approach. Survival outcomes were presented as pooled proportions while continuous outcomes were presented as pooled means, both with corresponding 95\% confidence intervals [CIs]. The primary outcome was in-hospital mortality. Secondary outcomes were duration of ECMO therapy and mechanical ventilation, weaning rate from ECMO and complications during ECMO.

Results: We included twenty-two observational studies with 1896 patients in the meta-analysis. Venovenous ECMO was the predominant mode used (98.6\%). The pooled in-hospital mortality in COVID-19 patients (22 studies, 1896 patients) supported with ECMO was $37.1 \%$ (95\% Cl 32.3-42.0\%, high certainty). Pooled mortality in the venovenous ECMO group was $35.7 \%$ (95\% Cl 30.7-40.7\%, high certainty). Meta-regression found that age and ECMO duration were associated with increased mortality. Duration of ECMO support (18 studies, 1844 patients) was 15.1 days (95\% $\mathrm{Cl} 13.4-18.7)$. Weaning from ECMO (17 studies, 1412 patients) was accomplished in $67.6 \%$ (95\% Cl 50.5-82.7\%) of patients. There were a total of $1583 \mathrm{ECMO}$ complications reported (18 studies, 1721 patients) and renal complications were the most common.

Conclusion: The majority of patients received venovenous ECMO support for COVID-19-related ARDS. In-hospital mortality in patients receiving ECMO support for COVID-19 was 37.1\% during the first year of the pandemic, similar to those with non-COVID-19-related ARDS. Increasing age was a risk factor for death. Venovenous ECMO appears to be an effective intervention in selected patients with COVID-19-related ARDS.
\end{abstract}

\footnotetext{
*Correspondence: ram ramanathan@nuhs.edu.sg

†Kollengode Ramanathan and Kiran Shekar have contributed equally to this work

${ }^{1}$ Yong Loo Lin School of Medicine, National University of Singapore, Singapore, Singapore
}

Full list of author information is available at the end of the article permits use, sharing, adaptation, distribution and reproduction in any medium or format, as long as you give appropriate credit to the original author(s) and the source, provide a link to the Creative Commons licence, and indicate if changes were made. The images or other third party material in this article are included in the article's Creative Commons licence, unless indicated otherwise in a credit line to the material. If material is not included in the article's Creative Commons licence and your intended use is not permitted by statutory regulation or exceeds the permitted use, you will need to obtain permission directly from the copyright holder. To view a copy of this licence, visit http://creativecommons.org/licenses/by/4.0/. The Creative Commons Public Domain Dedication waiver (http://creativeco mmons.org/publicdomain/zero/1.0/) applies to the data made available in this article, unless otherwise stated in a credit line to the data. 
PROSPERO CRD42020192627.

Keywords: Extracorporeal membrane oxygenation, Acute respiratory distress syndrome, COVID-19, SARS-CoV-2

\section{Introduction}

The use of extracorporeal membrane oxygenation (ECMO) for acute respiratory distress syndrome (ARDS) during outbreaks of emerging infections was previously reported during the 2009 influenza $\mathrm{A}(\mathrm{H} 1 \mathrm{~N} 1)$ pandemic, as well as the Middle East respiratory syndrome coronavirus (MERS-CoV) outbreaks [1-4]. More recently, there are reports on the use of ECMO in patients with coronavirus disease 2019 (COVID-19), who develop severe ARDS [5, 6]. The Extracorporeal Life Support Organisation (ELSO), the World Health Organization and the Surviving Sepsis Campaign (SSC) Guidelines recommend considering ECMO, in specialised centres, for patients with COVID-19 who develop severe ARDS. In addition, venovenous (VV) ECMO is recommended in selected patients who develop hypoxaemia that is refractory to optimal ventilator management and prone positioning, depending on the availability of resources [7-11].

Initial case reports and case series on the use of ECMO for COVID-19-related ARDS were disappointing and raised concerns regarding ECMO use in this patient population [12, 13]. However, several reports of ECMO use have subsequently emerged and have reported considerably better outcomes $[5,6,14,15]$. The first update of SSC guidelines published recently, suggested that ECMO should be considered only for carefully selected patients with COVID-19 and severe ARDS, with a weak strength of recommendation [16]. Given the resource implications of providing ECMO in a pandemic and variability in the reported outcomes, we performed a systematic review of the literature to summarise outcome data during the first year of the pandemic and identify risk factors for an unfavourable outcomes in order to guide clinical decisionmaking and further research.

\section{Methods}

\section{Search strategy and selection criteria}

This study was registered with PROSPERO (CRD42020192627) and was conducted in adherence with the Preferred Reporting Items for Systematic Reviews and Meta-analyses (PRISMA) Statement [17]. We searched MEDLINE, Embase, Cochrane and Scopus databases from 1 December 2019, to 10 January 2021, using the following keywords and their variations: "extracorporeal membrane oxygenation", "extracorporeal life support", "adult", "SARS-CoV-2" and "COVID-19" (Additional file 1: Table S1). We assessed all relevant studies and their citation lists to identify articles for inclusion.
We included data from all studies as well as available online national registries reporting on 10 or more adult patients with COVID-19 supported on ECMO. We excluded any animal or paediatric studies ( $<18$ years). In the case of overlapping patient data, we included the largest study and excluded any other overlapping studies. Studies from centres that contributed to the ELSO registry report [5] were also excluded to avoid duplication. Two reviewers (RRL and KR) independently screened the articles for eligibility by going through the titles and abstract. Full text of the shortlisted articles was searched thereafter; any conflicts were resolved by consensus or by a third reviewer (KS).

\section{Data collection}

Data were collected independently by two reviewers (RRL and KR) using a prespecified data extraction form; any conflicts were resolved by consensus or by a third reviewer (KS). Data collection covered study characteristics (study design, study duration, year of publication, name and country of origin of ECMO centre, indications for ECMO); patient demographics (number of patients, proportion of male/female patients, age, body mass index [BMI], comorbidities); pre-ECMO characteristics (ventilation parameters: partial pressure of arterial oxygen to fraction of inspired oxygen ratio $\left[\mathrm{PaO}_{2} / \mathrm{FiO}_{2}\right]$, serum $\mathrm{pH}$, lactate, duration of mechanical ventilation before ECMO initiation, adjunctive therapies, Sequential Organ Failure Assessment [SOFA] score); ECMO characteristics (type of ECMO at initiation, cannulation site, adjunctive therapies [prone positioning, neuromuscular blockade, inotropes/vasopressors, inhaled nitric oxide, corticosteroids and immunomodulatory agents]); mortality (in-hospital as well as substitution of the closest common mortality time point); and other relevant clinical outcomes (intensive care unit [ICU] and hospital length of stay [LOS], ECMO duration and complications during ECMO). Complications were represented broadly as per the ELSO reporting guidelines. Authors were contacted for additional data where necessary.

\section{Assessment of risk of bias and certainty of evidence}

Using the Joanna Briggs Institute (JBI) checklists for case series and cohort studies (Additional file 1: Table S2), we assessed studies for quality. We assessed the possibility of publication bias using Egger's test. We assessed statistical heterogeneity using the $I^{2}$ statistics, the Chi-squared test and visual inspection of the forest plots. We used the 
Grading of Recommendations, Assessments, Developments and Evaluations (GRADE) approach to assess the certainty of evidence[18, 19] (GRADEpro app available online: https://www.gradepro.org [accessed on 10 January 2021].

\section{Outcomes of interest}

The primary outcome was in-hospital mortality. Secondary outcomes were analysed in the overall cohort and included those remaining in hospital and on ECMO, ICU and hospital length of stay, duration of mechanical ventilation before ECMO, duration of ECMO and complications during ECMO.

\section{Statistical analysis}

We performed statistical analyses in $\mathrm{R} 3.6 .1$, using the meta (v4.12-0) and dmetar (v0.0.9000) packages [20-22]. For continuous variables, we pooled the means from the aggregate data presented in each study as per Wan et al. [23]. We anticipated significant interstudy heterogeneity given the varied presentation of COVID-19 and general lack of guidelines for patient management with ECMO during the early pandemic. As such, we conducted inverse-variance weighted random-effects meta-analyses (DerSimonian and Laird), and 95\% confidence intervals (CIs) were computed using the Clopper-Pearson method [24-26]. Survival outcomes are presented as pooled proportions, while continuous outcomes are presented as pooled means, both with corresponding 95\% CIs.

\section{Subgroup/sensitivity analysis}

We conducted planned subgroup analyses with continuity correction to include studies with zero events and include geographical region (Asia, Europe, North America and International). Summary-level meta-regression was conducted when at least 6 data points were collected to explore potential sources of heterogeneity or prognostically relevant prespecified study-level covariates [26]. Two sensitivity analyses were conducted for our metaanalysis: analysing the mortality among studies where all patients were supported with VV ECMO and another by excluding studies with a JBI score of less than 7 .

\section{Results}

\section{Study details and demographics}

Of 2259 references screened, we identified 37 potentially relevant studies and one national database that reported on the outcomes of ECMO in COVID-19 patients (Fig. 1) $[5,6,12-15,27-43]$. After excluding 11 studies with overlapping information, we included twenty-two retrospective observational studies with 1896 patients in the meta-analysis. There were 20 single-centre studies and two registry reports (Tables 1 and 2). There were 4 studies (422 patients) from Asia, 13 studies (320 patients) from Europe, 4 studies (102 patients) from North America and one multinational study (1035 patients). Modality of ECMO support was reported in 19 studies (1845 patients), and VV ECMO was the predominant technique used (98.6\%). In total, 89 patients required venoarterial or venoarterial venous configurations. The pooled patient demographics are summarised in Additional file 1: Table S3.

\section{Assessment of study quality}

Appraisal using the JBI checklist for cohort studies and case series suggested a high level of quality across the included studies for this review. All studies, except two [13, 32], had scores above 8/10 (Additional file 1: Table S2). A summary of the GRADE assessment for certainty of evidence is provided in Additional file 1: Table S4.

\section{Pre-ECMO variables}

Fifteen studies (1344 patients) reported on $\mathrm{PaO}_{2} / \mathrm{FiO}_{2}$ prior to ECMO initiation. The pooled mean $\mathrm{PaO}_{2} / \mathrm{FiO}_{2}$ was 67.76 (95\% CI 64.72-70.80). Pre-ECMO SOFA score was reported in 11 studies (275 patients) with a pooled mean SOFA score prior to ECMO initiation of 9.62 (95\% CI 8.40-10.84). The pre-ECMO ventilatory parameters are summarised in Additional file 1: Table S5.

\section{Pre-ECMO adjunctive therapies}

Patients with COVID-19 who received ECMO also received various adjunctive therapies prior to ECMO. Pooled incidence of prone positioning prior to ECMO was $85.3 \%$ (95\% CI $74.6-93.7 \%$ ) while $96.3 \%$ (95\% CI 87.6-100.0\%) of the patients received neuromuscular blockers. Additional details on the use of inotropic agents, corticosteroids, immuno-modulators and antiviral drugs are highlighted in Additional file 1: Table S6.

\section{In-hospital mortality}

The pooled in-hospital mortality of COVID-19 patients receiving ECMO (22 studies, 1896 patients) was 37.1\% (95\% CI 32.3-42.0\%, high certainty) (Fig. 2). Two studies had a JBI score lower than 8; pooled in-hospital mortality after excluding these studies was $37.9 \%$ (95\% CI 32.9-42.9\%). There was no evidence of publication bias (Fig. 3) $\left(\mathrm{p}_{\text {egger }}=0.21\right)$. We also analysed the proportion of non-survivors supported on VV ECMO for COVID19 (17 studies, 1737 patients); pooled in-hospital mortality was $35.7 \%$ (95\% CI 30.7-40.7\%, high certainty) (Additional file 2: Figure S1). Mortality, after removal of studies that did not report on pre-ECMO $\mathrm{PaO}_{2} /$ 


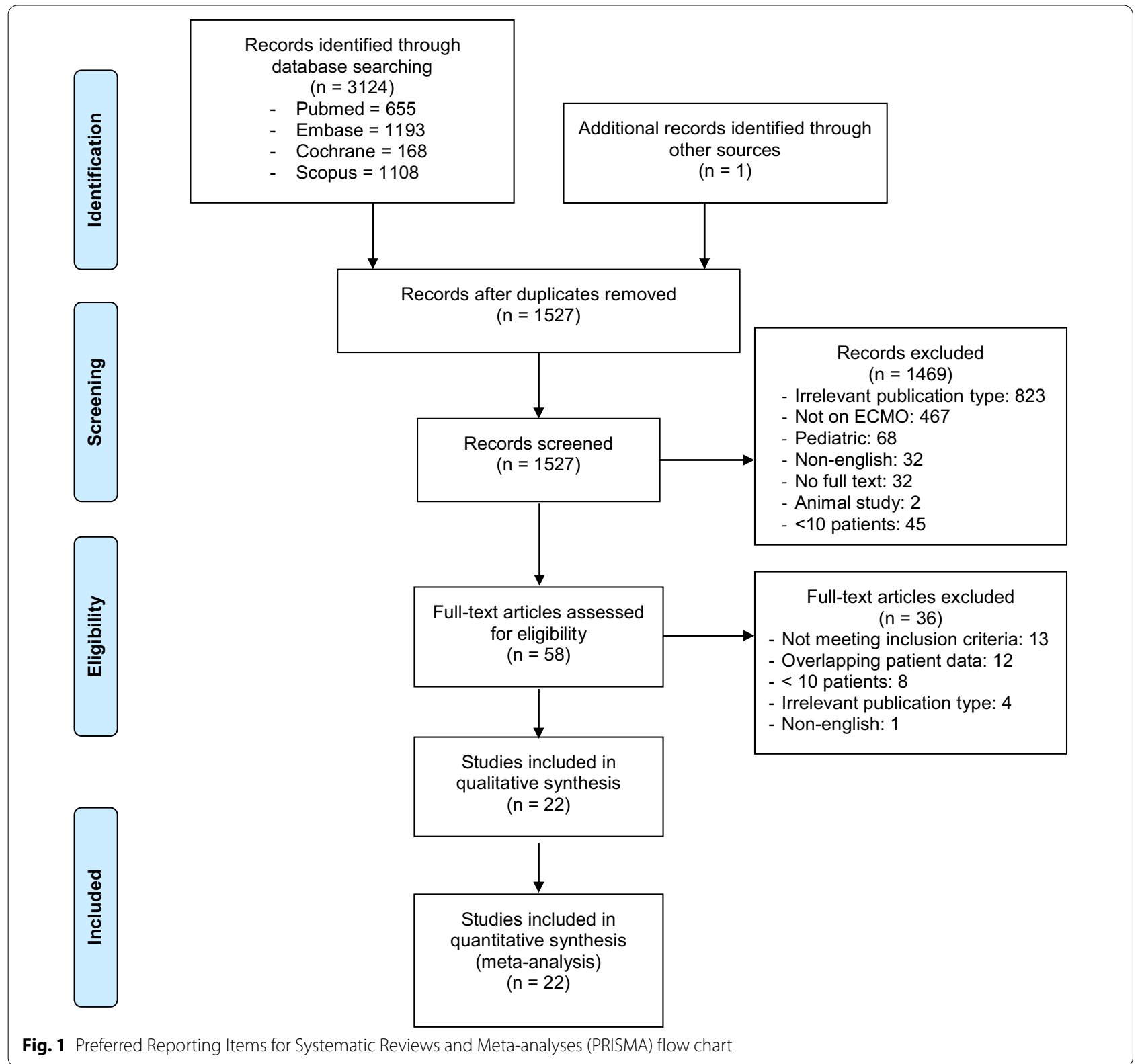

$\mathrm{FiO}_{2}$ ratio, was $36.4 \%$ (95\% CI 30.2-42.9\%). Two studies compared mortality rates of patients on mechanical ventilation to those on ECMO; patients needing mechanical ventilation had mortality rates of $47.8 \%$ and $63.2 \%$ as compared to $46.15 \%$ and $57.1 \%$, respectively, in those needing ECMO in these two studies.

\section{Subgroup analysis}

There were no overall differences in regional outcomes for COVID-19 patients treated with ECMO (Additional file 3: Figure S2).

\section{Meta-regression analysis}

Univariable meta-regression analysis identified increasing age and reduced ECMO duration as variables associated with mortality, while increasing BMI was protective (Additional file 4: Figure S3, Additional file 5: Figure S4 and Additional file 6: Figure S5). Increasing SOFA score was not associated with higher mortality. Other pre-ECMO factors $\left(\mathrm{PaO}_{2} / \mathrm{FiO}_{2}\right.$ ratio, duration of mechanical ventilation prior to ECMO) or coexisting comorbidities (diabetes mellitus, hypertension, smoking) were not associated with increased mortality (Table 3). 
Table 1 Demographics of the included studies

\begin{tabular}{|c|c|c|c|c|c|c|}
\hline First author & Country & $\begin{array}{l}\text { Number of } \\
\text { patients }\end{array}$ & Male patients n (\%) & Age* & VV ECMO & P/F ratio* \\
\hline Alnababteh & USA & 13 & $8(61.5)$ & $44.54 \pm 9.49$ & 13 & $97.96 \pm 49.87$ \\
\hline Akhtar & UK & 18 & $16(88.9)$ & $47.3 \pm 0.9$ & 18 & NR \\
\hline Barbaro & International & 1035 & $764(73.8)$ & $49(41-57)$ & 978 & $72(59-94)$ \\
\hline Charlton & UK & 34 & $27(79.4)$ & $46.3 \pm 7.5$ & 34 & $64.5(54.7-74.3)$ \\
\hline Cousin & France & 30 & $24(80)$ & $33.33 \pm 7.00$ & 30 & $69 \pm 9.34$ \\
\hline Falcoz & France & 17 & $16(94.1)$ & $56[30-76]$ & 16 & $71[52-134]$ \\
\hline Guihaire & France & 24 & $20(83.3)$ & $48.8 \pm 8.9$ & 24 & 67 [52-78] \\
\hline Huette & France & 12 & $12(100)$ & $62(58-64)$ & 14 & $76(66-83)$ \\
\hline Jackel & Germany & 15 & $11(73.3)$ & $60.8(54.2-67)$ & 15 & 63.7 (51.9-94.5) \\
\hline Jang & Korea & 19 & $15(79)$ & $63 \pm 4.81$ & 16 & $97.7 \pm 61.11$ \\
\hline Le Breton & France & 13 & $10(77)$ & $49.31 \pm 7.75$ & 13 & $60.62 \pm 15.23$ \\
\hline Jozwiak & France & 11 & $7(63.6)$ & $50(38-59)$ & 11 & $68(58-89)$ \\
\hline Masur & USA & 12 & $8(66.7)$ & $53.83 \pm 13.18$ & NR & NR \\
\hline Mustafa & USA & 40 & $30(75)$ & $48.4 \pm 1.5$ & 40 & $68.9 \pm 3.1$ \\
\hline Roedl & Germany & 20 & $N R$ & NR & 20 & NR \\
\hline Schmidt & France & 83 & $61(73.5)$ & $48.0 \pm 11.0$ & 81 & $62 \pm 18$ \\
\hline Shih & USA & 37 & $27(73.0)$ & $51(40-59)$ & 37 & $95(73-147)$ \\
\hline Takeda & Japan & 237 & $196(82.7)$ & NR & 230 & NR \\
\hline Yang & China & 21 & $12(57.1)$ & $58.5(42.75-67.25)$ & 21 & $60(55.6-72)$ \\
\hline Zayat & Germany & 17 & $11(64.7)$ & $57(53-62)$ & 17 & NR \\
\hline Zeng & China & 12 & $11(91.7)$ & $50.9 \pm 13.5$ & NR & NR \\
\hline Zhang & UK & 43 & $33(76.7)$ & $46(35.5-52.5)$ & 43 & 67.5 (58.9-77.8) \\
\hline
\end{tabular}

VV ECMO, venovenous extracorporeal membrane oxygenation; $\mathrm{P} / \mathrm{F}$, partial pressure of arterial oxygen to fraction of inspired oxygen ratio [PaO2/FiO2]; NR, not reported

${ }^{*}$ Age and $\mathrm{P} / \mathrm{F}$ ratio reported as mean $\pm \mathrm{SD}$, median (interquartile range) or median [range]

\section{Secondary outcomes}

In total, 141 of 1733 patients (21 studies) remained in hospital, while 68 of 1720 patients (20 studies) were still being supported with ECMO at the time of publication. Pooled ICU LOS (8 studies, 216 patients) and hospital LOS (6 studies, 1177 patients) were 32 days (95\% CI 26-38, moderate certainty) and 40 days (95\% CI 30-49, low certainty), respectively. There were 17 studies (1412 patients) that reported on weaning from ECMO with $67.6 \%$ (95\% CI 50.5-82.7\%, low certainty) of patients successfully weaned off ECMO. The pooled mean duration of mechanical ventilation prior to ECMO (16 studies, 1427 patients) was 4.40 days (95\% CI 4.03-4.79, moderate certainty), while the pooled ECMO duration (18 studies, 1711 patients) was 15.81 days (95\% CI 13.26-18.35, moderate certainty). Complications during ECMO were reported in 18 studies (1721 patients). There were a total of 1583 reported complications; renal complications (559/1583) were the most common, followed by mechanical $(429 / 1583)$ and infectious complications (171/1583). A summary of all the outcomes including complications is provided in Table 2.

\section{Discussion}

This systematic review and meta-analysis examined the use of ECMO in adult patients with COVID-19 during the first year of the pandemic. The pooled in-hospital mortality in 1896 patients with COVID-19 who predominantly had severe ARDS and were supported with ECMO was $37 \%$, and this estimate was based on high certainty evidence. Mortality was slightly lower $(35.7 \%)$ in patients exclusively receiving VV ECMO. This pooled mortality rate is comparable to the mortality rates seen in ECMO treated patients in the ECMO to Rescue Lung Injury in Severe ARDS [EOLIA] and Conventional ventilation or ECMO for Severe Adult Respiratory failure [CESAR] trials $[44,45]$ as well as the recent individual patient data meta-analysis of the two randomised controlled trials evaluating the use of VV ECMO in patients with ARDS from non-COVID etiologies (32.1 vs. 36\%) [46]. The pooled mean duration of ECMO support in COVID-19 patients was 16 days, and the pooled mean ICU length of stay was 29 days. A large proportion of patients received neuromuscular blockade $(96.2 \%)$ and were positioned prone $(84.5 \%)$ prior to initiation of ECMO. The 
Table 2 Outcomes of the included studies

\begin{tabular}{|c|c|c|c|c|c|c|}
\hline First author & Mortality & Survivors & Not discharged & Still on ECMO & Complications on ECMO & Days on ECMO* \\
\hline Alnababteh & 6 & 4 & 3 & NR & $\begin{array}{l}3 \text { mechanical } \\
7 \text { haemorrhagic } \\
6 \text { renal } \\
4 \text { pulmonary } \\
2 \text { infectious } \\
3 \text { metabolic } \\
2 \text { limb }\end{array}$ & $12.85 \pm 6.04$ \\
\hline Akhtar & 4 & 14 & 0 & 0 & & $17.7 \pm 9.4$ \\
\hline Barbaro & 380 & 588 & 67 & 31 & $\begin{array}{l}295 \text { mechanical } \\
69 \text { neurologic } \\
444 \text { renal }\end{array}$ & $13.9(7.8-23.3)$ \\
\hline Charlton & 16 & 18 & 0 & 0 & & \\
\hline Cousin & 16 & NR & NR & $N R$ & $\begin{array}{l}8 \text { mechanical } \\
27 \text { haemorrhagic } \\
4 \text { neurologic } \\
15 \text { renal } \\
2 \text { pulmonary } \\
4 \text { infectious } \\
3 \text { limb }\end{array}$ & $10.67 \pm 5.45$ \\
\hline Falcoz & 6 & 10 & 1 & 0 & $\begin{array}{l}7 \text { mechanical } \\
62 \text { haemorrhagic } \\
1 \text { neurologic } \\
12 \text { renal } \\
1 \text { cardiovascular } \\
3 \text { pulmonary } \\
10 \text { infectious } \\
1 \text { others (thrombocytopenia) }\end{array}$ & $9[0-16]$ \\
\hline Guihaire & 4 & 16 & 4 & 3 & $\begin{array}{l}18 \text { mechanical } \\
1 \text { neurologic } \\
10 \text { pulmonary } \\
3 \text { infectious } \\
1 \text { other (mesenteric ischemia) }\end{array}$ & $19.0 \pm 10.1$ \\
\hline Huette & 4 & 8 & 0 & 0 & $\begin{array}{l}5 \text { mechanical } \\
3 \text { hemorrhagic } \\
8 \text { renal } \\
1 \text { cardiovascular } \\
4 \text { pulmonary } \\
10 \text { infectious } \\
3 \text { others ( } 2 \text { liver failure, } 1 \text { HIT) }\end{array}$ & $12(9-22)$ \\
\hline Jackel & 8 & 7 & 0 & 0 & & \\
\hline Jang & 10 & 4 & 5 & 2 & $\begin{array}{l}5 \text { neurologic } \\
9 \text { renal } \\
1 \text { cardiovascular } \\
6 \text { pulmomary }\end{array}$ & $17.27 \pm 16.42$ \\
\hline Jozwiak & 6 & 5 & 0 & 0 & & \\
\hline Le Breton & 2 & 11 & 0 & 0 & $\begin{array}{l}2 \text { mechanical } \\
3 \text { hemorrhagic } \\
2 \text { infectious }\end{array}$ & $14.53 \pm 8.84$ \\
\hline Masur & 5 & 1 & 6 & NR & 6 neurologic & 9.60 \\
\hline Mustafa & 6 & 29 & 5 & 2 & 10 pulmonary & $29.9 \pm 3.6$ \\
\hline Roedl & 13 & 7 & 0 & 0 & & \\
\hline Schmidt & 25 & 38 & 20 & 5 & $\begin{array}{l}25 \text { mechanical } \\
45 \text { hemorrhagic } \\
5 \text { neurologic } \\
38 \text { renal } \\
11 \text { cardiovascular } \\
50 \text { pulmonary } \\
129 \text { infectious } \\
7 \text { others ( } 5 \text { thrombocytopenia, } 2 \text { HIT) }\end{array}$ & $20(10-40)$ \\
\hline Shih & 16 & 21 & 0 & 0 & & \\
\hline
\end{tabular}


Table 2 (continued)

\begin{tabular}{|c|c|c|c|c|c|c|}
\hline First author & Mortality & Survivors & Not discharged & Still on ECMO & Complications on ECMO & Days on $\mathrm{ECMO}^{*}$ \\
\hline Takeda & 67 & NR & 20 & 20 & NA & $14.42 \pm 9.01$ \\
\hline Yang & 12 & 6 & 3 & 0 & $\begin{array}{l}3 \text { hemorrhagic } \\
8 \text { renal } \\
8 \text { cardiovascular } \\
6 \text { pulmonary } \\
3 \text { infectious }\end{array}$ & NR \\
\hline Zayat & 8 & 9 & 0 & 0 & & \\
\hline Zeng & 5 & $N R$ & 7 & 4 & NA & $11.3 \pm 7.8$ \\
\hline Zhang & 14 & 29 & 0 & 0 & & \\
\hline
\end{tabular}

ECMO, extracorporeal membrane oxygenation; NR, not reported

*Days on $\mathrm{ECMO}$ reported as mean $\pm \mathrm{SD}$, median (interquartile range) or median [range]

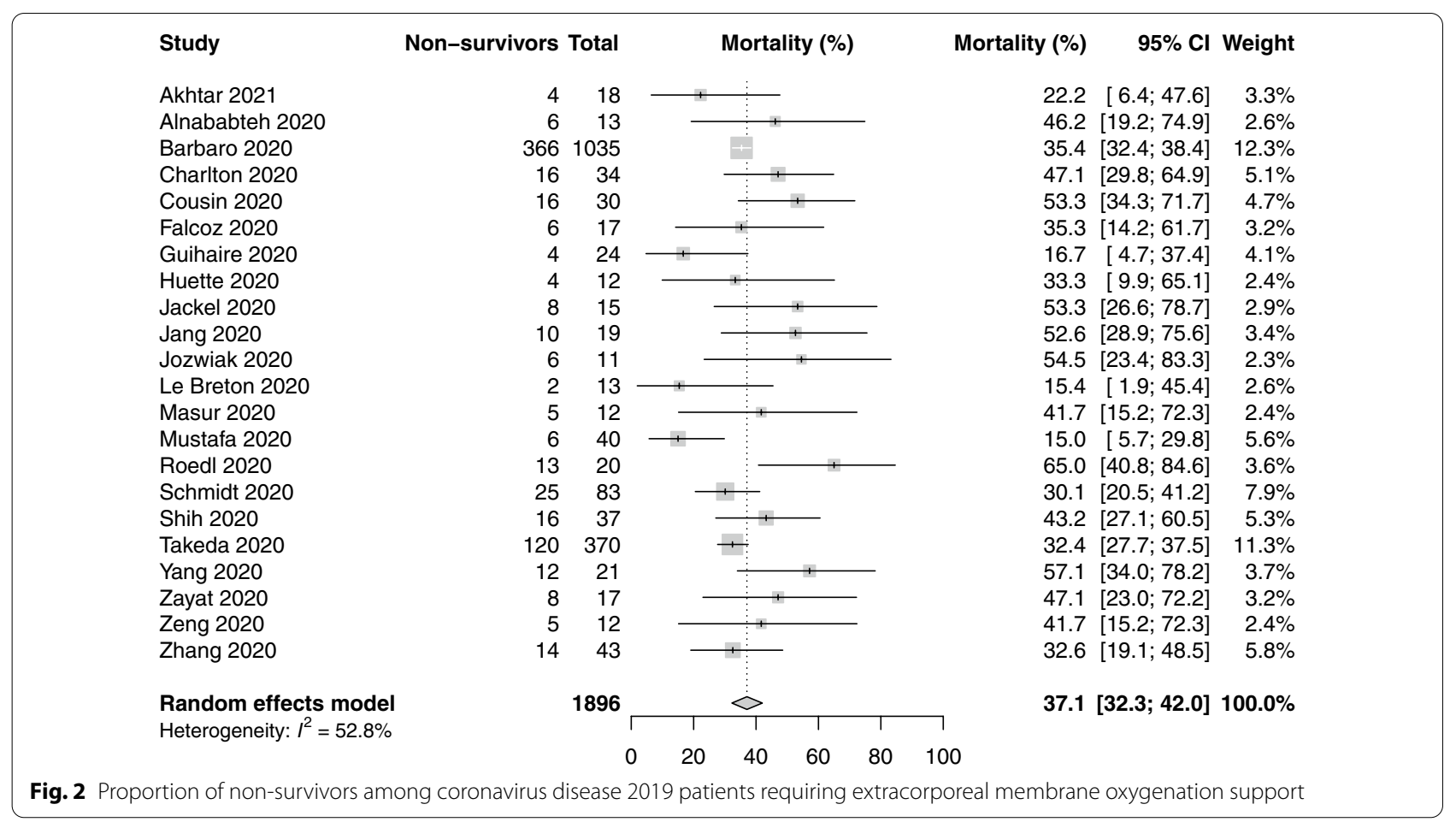

patients more commonly suffered renal, mechanical and infectious complications, and the complication rates in COVID-19 patients were similar to those seen in the EOLIA trial [44]. The review also identified increasing age as a risk factor for increased mortality.

The use and efficacy of ECMO in pandemics have been previously reported [1-3]. The incidence of ECMO use in patients with 2009 influenza $\mathrm{A}(\mathrm{H} 1 \mathrm{~N} 1)$-associated ARDS in Australia and New Zealand was estimated to be $2-6$ cases per million $[1,8]$, whereas $6 \%$ of critically ill patients were supported with ECMO for MERS-CoVassociated ARDS [4]. A meta-analysis of the studies that reported on the use of ECMO for the 2009 influenza
A(H1N1) pandemic showed an overall mortality of $35 \%$ in a relatively younger population (mean age 40 years) [2]. Patients with MERS-CoV who were supported with ECMO had a higher reported mortality of $40-70 \%$ [3]. By comparison, this review demonstrated that the cumulative mortality for patients with COVID-19 receiving ECMO support was $37.1 \%$ in a group of patients who were older (mean age 51.6 years) and were predominantly men. These results may also alleviate some concerns regarding VV ECMO use in the context of COVID-19-related ARDS [13, 47]. During a pandemic, ECMO use will be subject to resource availability, given that prolonged ECMO support may be needed in these 


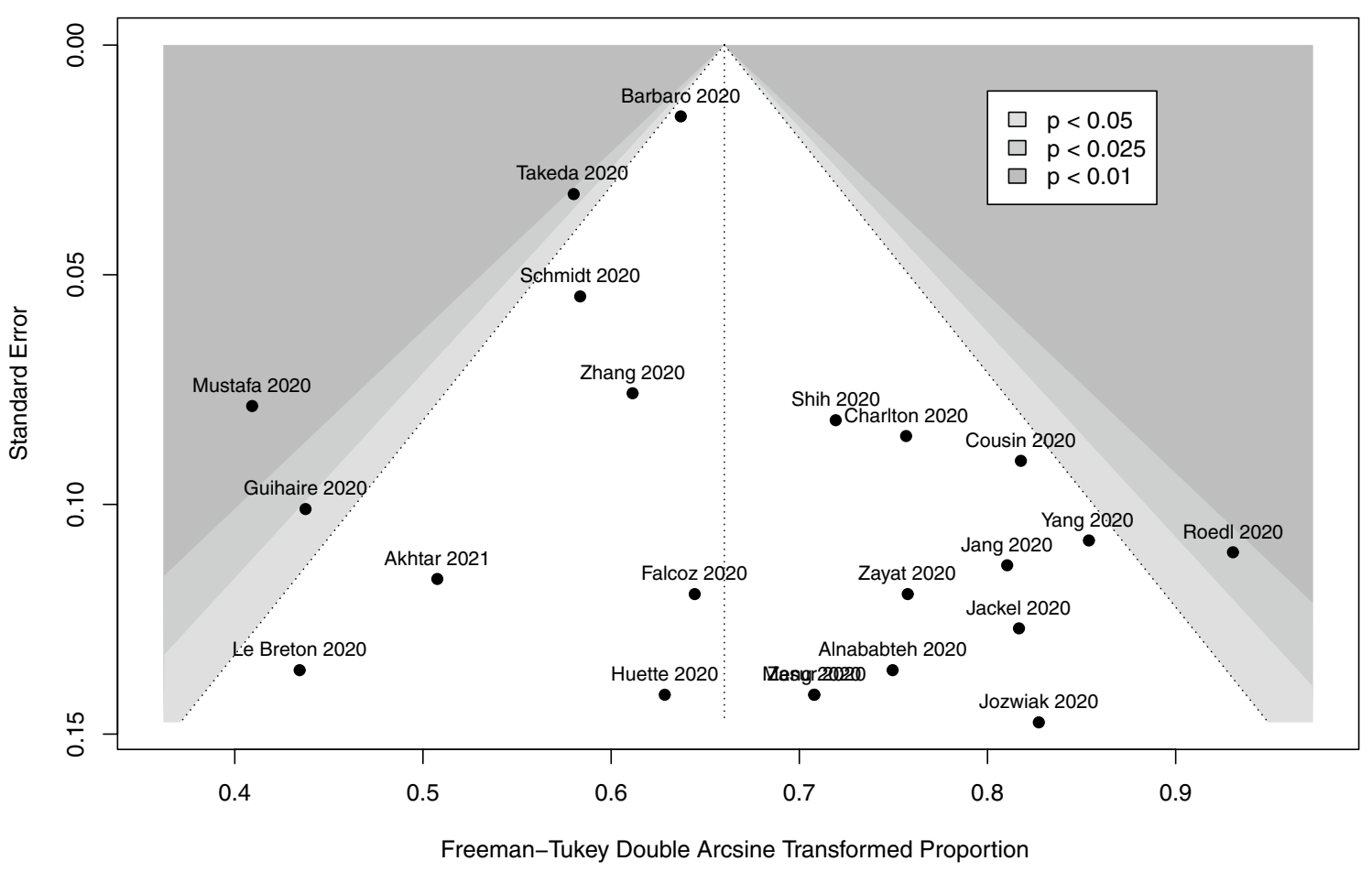

Fig. 3 Funnel plot for primary meta-analysis

Table 3 Results of meta-regression analyses

\begin{tabular}{llllll}
\hline Covariate & Studies & OR & LCI & UCI & P \\
\hline ECMO duration & 19 & 0.987 & 0.979 & 0.994 & $\mathbf{0 . 0 0 1}$ \\
Age & 20 & 1.014 & 1.003 & 1.024 & $\mathbf{0 . 0 1}$ \\
BMI & 16 & 0.977 & 0.956 & 0.999 & $\mathbf{0 . 0 4}$ \\
Male & 21 & 0.566 & 0.314 & 1.017 & 0.06 \\
Smoking & 7 & 0.360 & 0.105 & 1.232 & 0.10 \\
P/F ratio & 15 & 1.003 & 0.998 & 1.007 & 0.25 \\
Sample size & 22 & 1.000 & 1.000 & 1.000 & 0.59 \\
SOFA score & 11 & 0.991 & 0.951 & 1.033 & 0.66 \\
Ventilation-to- & 16 & 0.997 & 0.945 & 1.051 & 0.90 \\
$\quad$ ECMO interval & & & & & \\
DM & 19 & 1.018 & 0.645 & 1.606 & 0.94 \\
HTN & 18 & 0.987 & 0.648 & 1.502 & 0.95 \\
\hline
\end{tabular}

p-values: $\mathrm{p}<0.05$ represented in bold

OR, Odds ratio; LCl, lower $95 \%$ confidence interval; UCI, upper $95 \%$ confidence interval; P, p-value; ECMO, extracorporeal membrane oxygenation; SOFA, Sequential Organ Failure Assessment; BMI, body mass index; DM, diabetes mellitus; P/F, PaO2/FiO2; $\mathrm{HTN}$, hypertension

patients and the ELSO guidelines provide recommendations to assist clinicians in selecting patients judiciously in order to maximise benefit to patients with available resources $[7,8]$. Our meta-regression analysis showed that outcomes appear worse in patients with increasing age. Clinicians may have to exercise considerable discretion when offering ECMO to older patients during a pandemic where resources may be stretched, with no definitive age cut-off to guide this decision-making.

Interestingly, greater duration of ECMO support and illness severity (SOFA score) were not independently associated with death. The duration of VV ECMO support was longer when compared with patients in the EOLIA trial receiving ECMO (median: 15.92 days vs 11 days). Prolonged ECMO runs outside COVID-19 have been reported with good success [48]. However, the association between prolonged ECMO duration and improved mortality seen in this study stems likely from immortal time bias[49](49), commonly reported in observational studies. For patients on ECMO, such individuals must survive long enough to be weaned off, whereas their peers have no minimum survival requirements. The mean duration of mechanical ventilation prior to ECMO was 4.4 days and was not associated with mortality in the meta-regression analysis. Higher SOFA score was not an independent predictor for death in this review, a finding that contradicts previously published experience [50]. SOFA scores in patients requiring ECMO for COVID-19 can be variable, depending on their underlying phenotype [51]. Therefore, caution should be exercised when placing patients with advanced extrapulmonary organ failures on ECMO. Even though VV ECMO appears to be a viable therapy, the potential need for prolonged ECMO 
support may be a significant consideration when selecting patients during the pandemic. Other uncertainties regarding the long-term outcomes and the maximum duration of ECMO where recovery is still possible remain and may become clearer as more data becomes available [52].

Strengths of this study include robust inclusion criteria and relevant exclusion criteria. Our review included 22 studies covering 6 geographical regions. We reduced confounding by elucidating factors correlating with mortality via subgroup analysis and meta-regression. Singlecentre data that overlapped with international registries were excluded thereby avoiding duplication of data. We assessed study quality using a validated tool and assessed certainty in our estimates using GRADE. Nonetheless, we recognise several limitations of this study. Firstly, we included studies written only in English for the review. The variability in ECMO initiation and management across centres and regions as well as additional variability during the pandemic may have contributed to increased heterogeneity in our results. The outcomes of patients who were still in hospital or on ECMO at the time of publication were not known. Given that most of these studies were single-centre retrospective studies, these aspects could have introduced various confounders given the lack of risk adjustment or propensity score weighting. Even though the paper from ELSO registry contributed to a majority of patients in the review, the overall weightage to the entire analysis was only $12 \%$, highlighting that the data were not skewed by one study. In addition, manuscripts published from centres that contributed to the ELSO registry report were excluded to avoid duplication. Meta-regression analyses are also inherently constrained by a lack of power, resulting in an increased risk of type 2 errors. This is further compounded by the fact that certain important variables, such as pre-ECMO SOFA scores, were only available in 11 studies, which might reduce the strength of the association between these variables and mortality Nonetheless, there was no publication bias in the studies included and JBI critical appraisal deemed most of the articles as high quality and suitable for inclusion while the GRADE assessment suggested a high certainty of evidence for the primary outcome.

\section{Conclusions}

The outcomes from VV ECMO use in patients with COVID-19-related severe ARDS during the early pandemic appear similar to those reported in patients who receive VV ECMO for non-COVID-19-related severe ARDS. Increasing age is a risk factor for death. The duration of ECMO appears to be prolonged in patients with COVID-19 and a prolonged ECMO run was not in itself a predictor of death.

\section{Abbreviations}

ECMO: Extracorporeal membrane oxygenation; ARDS: Acute respiratory distress syndrome; MERS-CoV: Middle East respiratory syndrome coronavirus; COVID-19: Coronavirus disease 2019; ELSO: Extracorporeal Life Support Organisation; SSC: Surviving Sepsis Campaign; W: Venovenous; PROSPERO The International Prospective Register of Systematic Reviews; PRISMA: Preferred Reporting Items for Systematic Reviews and Meta-analyses; BMI: Body mass index; SOFA: Sequential Organ Failure Assessment; ICU: Intensive care unit; LOS: Length of stay; JBI: Joanna Briggs Institute; GRADE: Grading of Recommendations, Assessment, Development and Evaluations; EOILA: Extracorporeal membrane oxygenation for severe acute respiratory distress syndrome; CESAR: Conventional ventilatory support vs extracorporeal membrane oxygenation for severe adult respiratory failure.

\section{Supplementary Information}

The online version contains supplementary material available at https://doi. org/10.1186/s13054-021-03634-1.

Additional file 1. Supplementary Tables: Table S1 to S6.

Additional file 2: Fig. S1. Proportion of non-survivors among COVID-19 patients supported with venovenous ECMO.

Additional file 3: Fig. S2. Proportion of non-survivors among COVID-19 patients supported with ECMO stratified by geographical region.

Additional file 4: Fig. S3. Bubble plot correlating mean age and proportion of non-survivors.

Additional file 5: Fig. S4. Bubble plot correlating mean BMI and proportion of non-survivors.

Additional file 6: Fig. S5. Bubble plot correlating ECMO duration and proportion of non-survivors.

\section{Acknowledgements}

The authors would like to acknowledge Satoru Hashimoto for his help with the analysis of the ECMO patients on the live dashboard at the Japan ECMOnet for COVID-19 website. Dr Shekar acknowledges research support from Metro North Hospital and Health Service.

\section{Authors' contributions}

The study was designed by KS and KR. RRL and KR screened the articles, assessed the risk of bias and extracted the data. RPB and ST aided with the data from Extracorporeal Life Support Organisation and Japan ECMOnet for COVID-19 registries, respectively. SNW helped with the search criteria. RRL analysed and interpreted the data under the supervision of CST and KR. BR and SF helped with GRADE analysis. Tables and figures were produced by RRL. $\mathrm{KR}$ and $\mathrm{KS}$ had primary responsibility of writing the manuscript, to which all authors contributed to and revised. DB, EF, RPB and GM critically revised the manuscript for important intellectual content. All authors provided critical conceptual input, interpreted the data analysis, read and approved the final draft.

\section{Funding}

Not applicable.

\section{Availability of data and materials}

All data generated or analysed during this study are included in the published studies and their supplementary information files.

\section{Declarations}

Ethics approval and consent to participate Not applicable.

\section{Consent for publication}

Not applicable. 


\section{Competing interests}

DB receives research support from ALung Technologies. He has been on the medical advisory boards for Baxter, Abiomed, Xenios and Hemovent, and is the President-elect of ELSO. RPB receives research support unrelated to this project from National Institutes of Health's National Heart, Lung and Blood Institute K12 HL138039 and R01 HL153519 and the National Institute of Child Health and Human Development R01 HD015434. He is the ELSO Registry Chair. EF reports personal fees from ALung Technologies, Baxter, Fresenius Medical Care, Getinge and MC3 Cardiopulmonary outside the submitted work.

\section{Author details}

${ }^{1}$ Yong Loo Lin School of Medicine, National University of Singapore, Singapore, Singapore. ${ }^{2}$ Cardiothoracic Intensive Care Unit, National University Heart Centre, National University Hospital, Singapore 119228, Singapore. ${ }^{3}$ Adult Intensive Care Services, Prince Charles Hospital, Brisbane, QLD, Australia. ${ }^{4}$ Queensland University of Technology, Brisbane, Australia. ${ }^{5}$ University of Queensland, Brisbane, Australia. ${ }^{6}$ Bond University, Gold Coast, QLD, Australia. ${ }^{7}$ Division of Paediatric Critical Care Medicine, University of Michigan, Ann Arbor, USA. ${ }^{8}$ Child Health Evaluation and Research Center, University of Michigan, Ann Arbor, MI, USA. ${ }^{9}$ Saw Swee Hock School of Public Health, National University of Singapore, Singapore, Singapore. ${ }^{10}$ Department of Medicine, Division of Critical Care, McMaster University, Hamilton, ON, Canada. ${ }^{11}$ Department of Health Research Methods, Evidence and Impact, McMaster University, Hamilton, ON, Canada. ${ }^{12}$ Division of Critical Care, Department of Medicine, University of Ottawa, Ottawa, ON, Canada. ${ }^{13}$ Japan ECMOnet for COVID-19 \& President, Kawaguchi Cardiovascular and Respiratory Hospital, Saitama, Japan. ${ }^{14}$ Interdepartmental Division of Critical Care Medicine, University of Toronto, Toronto, Canada. ${ }^{15}$ Department of Medicine, Columbia University College of Physicians and Surgeons, New York, NY, USA. ${ }^{16}$ Center for Acute Respiratory Failure, New York-Presbyterian Hospital, New York, NY, USA

Received: 29 March 2021 Accepted: 7 June 2021

Published online: 14 June 2021

\section{References}

1. Australia, New Zealand Extracorporeal Membrane Oxygenation Influenza I, Davies A, Jones D, Bailey M, Beca J, Bellomo R, Blackwell N, Forrest P, Gattas D et al: Extracorporeal membrane oxygenation for 2009 influenza $\mathrm{A}(\mathrm{H} 1 \mathrm{~N} 1)$ acute respiratory distress syndrome. JAMA 2009 , 302(17):1888-95.

2. Sukhal S, Sethi J, Ganesh M, Villablanca PA, Malhotra AK, Ramakrishna $H$. Extracorporeal membrane oxygenation in severe influenza infection with respiratory failure: a systematic review and meta-analysis. Ann Card Anaesth. 2017;20(1):14-21.

3. Alshahrani MS, Sindi A, Alshamsi F, Al-Omari A, El Tahan M, Alahmadi B, Zein A, Khatani N, Al-Hameed F, Alamri S, et al. Extracorporeal membrane oxygenation for severe Middle East respiratory syndrome coronavirus. Ann Intensive Care. 2018;8(1):3.

4. Cho HJ, Heinsar S, Jeong IS, Shekar K, Li Bassi G, Jung JS, Suen JY, Fraser JF. ECMO use in COVID-19: lessons from past respiratory virus outbreaks-a narrative review. Crit Care. 2020;24(1):301.

5. Barbaro RP, MacLaren G, Boonstra PS, Iwashyna TJ, Slutsky AS, Fan E, Bartlett RH, Tonna JE, Hyslop R, Fanning JJ, et al. Extracorporeal membrane oxygenation support in COVID-19: an international cohort study of the Extracorporeal Life Support Organization registry. Lancet. 2020;396(10257):1071-8.

6. Schmidt M, Hajage D, Lebreton G, Monsel A, Voiriot G, Levy D, Baron E, Beurton A, Chommeloux J, Meng P, et al. Extracorporeal membrane oxygenation for severe acute respiratory distress syndrome associated with COVID-19: a retrospective cohort study. Lancet Respir Med. 2020:8(11):1121-31.

7. Shekar K, Badulak J, Peek G, Boeken U, Dalton HJ, Arora L, Zakhary B, Ramanathan K, Starr J, Akkanti B, et al. Extracorporeal Life Support Organization Coronavirus Disease 2019 Interim Guidelines: a consensus document from an international group of interdisciplinary extracorporea membrane oxygenation providers. ASAIO J. 2020;66(7):707-21.

8. Ramanathan K, Antognini D, Combes A, Paden M, Zakhary B, Ogino M, MacLaren G, Brodie D, Shekar K. Planning and provision of ECMO services for severe ARDS during the COVID-19 pandemic and other outbreaks of emerging infectious diseases. Lancet Respir Med. 2020;8(5):518-26.

9. Infection prevention and control during health care when novel coronavirus ( $\mathrm{nCOV}$ ) infection is suspected: Interim guidance. https://www.who. int/publications-detail/infection-prevention-and-control-during-healthcare-when-novel-coronavirus-(ncov)-infection-is-suspected-20200125.

10. Alhazzani W, Moller MH, Arabi YM, Loeb M, Gong MN, Fan E, Oczkowski S, Levy MM, Derde L, Dzierba A, et al. Surviving Sepsis Campaign: guidelines on the management of critically ill adults with Coronavirus Disease 2019 (COVID-19). Intensive Care Med. 2020;46(5):854-87.

11. Fernando SM, Qureshi D, Tanuseputro P, Fan E, Munshi L, Rochwerg B, Talarico R, Scales DC, Brodie D, Dhanani S, et al. Mortality and costs following extracorporeal membrane oxygenation in critically ill adults: a population-based cohort study. Intensive Care Med. 2019;45(11):1580-9.

12. Yang X, Cai S, Luo Y, Zhu F, Hu M, Zhao Y, Zheng R, Li X, Hu B, Peng $Z$. Extracorporeal membrane oxygenation for coronavirus disease 2019-induced acute respiratory distress syndrome: a multicenter descriptive study. Crit Care Med. 2020;48:1289-95.

13. Zeng Y, Cai Z, Xianyu Y, Yang BX, Song T, Yan Q. Prognosis when using extracorporeal membrane oxygenation (ECMO) for critically ill COVID-19 patients in China: a retrospective case series. Crit Care. 2020;24(1):148.

14. Takeda S. Nationwide system to centralize decisions around extracorporeal membranous oxygenation use for severe COVID-19 pneumonia in Japan. Acute Med Surg. 2020;7(1):e510.

15. Mustafa AK, Alexander PJ, Joshi DJ, Tabachnick DR, Cross CA, Pappas PS, Tatooles AJ. Extracorporeal membrane oxygenation for patients with COVID-19 in severe respiratory failure. JAMA Surg. 2020;155:190.

16. EL Alhazzani W, Alshamsi F, Møller MH, Otermann M, Prescott HC, Arabi YM. Surviving Sepsis Campaign Guidelines on the management of adults with coronavirus disease 2019 (COVID-19) in the ICU: first update. Crit Care Med. 2021:48:e440-69.

17. Moher D, Liberati A, Tetzlaff J, Altman DG, Group P. Preferred reporting items for systematic reviews and meta-analyses: the PRISMA statement. BMJ. 2009;339:b2535.

18. Guyatt GH, Oxman AD, Kunz R, Woodcock J, Brozek J, Helfand M, Alonso-Coello P, Glasziou P, Jaeschke R, Akl EA, et al. GRADE guidelines: 7. Rating the quality of evidence-inconsistency. J Clin Epidemiol. 2011;64(12):1294-302.

19. Iorio A, Spencer FA, Falavigna M, Alba C, Lang E, Burnand B, McGinn T, Hayden J, Williams K, Shea B, et al. Use of GRADE for assessment of evidence about prognosis: rating confidence in estimates of event rates in broad categories of patients. BMJ. 2015:350:h870.

20. Bateman ED, Fairall L, Lombardi DM, English R. Budesonide/formoterol and formoterol provide similar rapid relief in patients with acute asthma showing refractoriness to salbutamol. Respir Res. 2006;7:13.

21. Harper MD, Koerner M, El Banayosy A. VA-ECMO for post-cardiotomy cardiogenic shock: The Oklahoma ECMO Network Experience. ASAIO J. 2017;63(5):21.

22. Schuster DP, Lange NR, Tutuncu A, Wedel M. Clinical correlation with changing radiographic appearance during partial liquid ventilation. Chest. 2001:119(5):1503-9.

23. Wan X, Wang W, Liu J, Tong T. Estimating the sample mean and standard deviation from the sample size, median, range and/or interquartile range. BMC Med Res Methodol. 2014;14:135

24. DerSimonian R, Laird N. Meta-analysis in clinical trials. Control Clin Trials. 1986;7(3):177-88

25. Clopper CJ, Pearson ES. The use of confidence or fiducial limits illustrated in the case of the binomial. Biometrika. 1934;26(4):404-13.

26. Jia D, Yang IX, Ling RR, Syn N, Poon WH, Murughan K, Tan CS, Choong A, MacLaren G, Ramanathan K. Vascular complications of extracorporeal membrane oxygenation: a systematic review and meta-regression analysis. Crit Care Med. 2020:48:e1269-77.

27. Alnababteh M, Hashmi MD, Vedantam K, Chopra R, Kohli A, Hayat F, Kriner E, Molina E, Pratt A, Oweis E et al. Extracorporeal membrane oxygenation for COVID-19 induced hypoxia: single-center study. Perfusion. 2020 https://doi.org/10.1177/0267659120963885.

28. Akhtar W, Olusanya O, Baladia MM, Young H, Shah S. SARS-CoV-2 and ECMO: early results and experience. Indian J Thorac Cardiovasc Surg. 2021:37(1):53-60.

29. Charlton M, Dashey S, Stubbs A, Lai FY, Bird PW, Badhwar V, Tang JW. Comparing SARS-CoV-2 and influenza A(H1N1)pdm09-infected patients 
requiring $\mathrm{ECMO}$ - a single-centre, retrospective observational cohort experience. J Infect. 2020;82:84-123.

30. Cousin N, Bourel C, Carpentier D, Goutay J, Mugnier A, Labreuche J, Godeau E, Clavier T, Grange S, Tamion F, et al. SARS-CoV-2 versus influenza associated acute respiratory distress syndrome requiring veno-venous extracorporeal membrane oxygenation support. ASAIO J. 2020;67:125-31.

31. Falcoz PE, Monnier A, Puyraveau M, Perrier S, Ludes PO, Olland A, Mertes PM, Schneider F, Helms J, Meziani F. Extracorporeal membrane oxygenation for critically ill patients with COVID-19-related acute respiratory distress syndrome: worth the effort? Am J Respir Crit Care Med. 2020;202(3):460-3.

32. Guihaire J, Owyang CG, Madhok J, Laverdure F, Gaillard M, Girault A, Lebreton G, Mercier O. Specific considerations for venovenous extracorporeal membrane oxygenation during coronavirus disease 2019 pandemic. ASAIO J. 2020;66(10):1069-72.

33. Huette P, Beyls C, Guilbart M, Coquet A, Berna P, Haye G, Roger PA, Besserve P, Bernasinski M, Dupont H, et al. Extracorporeal membrane oxygenation for respiratory failure in COVID-19 patients: outcome and time-course of clinical and biological parameters. Can J Anaesth. 2020;67(10):1486-8.

34. Jäckel M, Rilinger J, Lang CN, Zotzmann V, Kaier K, Stachon P, Biever PM, Wengenmayer T, Duerschmied D, Bode C, et al. Outcome of acute respiratory distress syndrome requiring extracorporeal membrane oxygenation in Covid-19 or influenza: a single-center registry study. Artif Organs. 2020;45:593-601.

35. Jang WS, Kim J, Baek J, et al. Clinical course of COVID-19 patients treated with ECMO: a multicenter study in Daegu. South Korea Heart and Lung. 2020;50:21-7.

36. Le Breton C, Besset S, Freita-Ramos S, Amouretti M, Billiet PA, Dao M, Dumont LM, Federici L, Gaborieau B, Longrois D, et al. Extracorporeal membrane oxygenation for refractory COVID-19 acute respiratory distress syndrome. J Crit Care. 2020;60:10-2.

37. Jozwiak M, Chiche JD, Charpentier J, Ait Hamou Z, Jaubert P, Benghanem S, Dupland P, Gavaud A, Péne F, Cariou A, et al. Use of venovenous extracorporeal membrane oxygenation in critically-ill patients with COVID-19. Front Med (Lausanne). 2020;7:614569-73.

38. Masur J, Freeman CW, Mohan S. A double-edged sword: neurologic complications and mortality in extracorporeal membrane oxygenation therapy for COVID-19-related severe acute respiratory distress syndrome at a tertiary care center. AJNR Am J Neuroradiol. 2020;41(11):2009-11.

39. Roedl K, Jarczak D, Thasler L, Bachmann M, Schulte F, Bein B, Weber CF, Schäfer U, Veit C, Hauber HP, et al. Mechanical ventilation and mortality among 223 critically ill patients with coronavirus disease 2019: a multicentric study in Germany. Aust Crit Care. 2020;34:167-75.

40. Shih E, DiMaio JM, Squiers JJ, Banwait JK, Meyer DM, George TJ, Schwartz GS. Venovenous extracorporeal membrane oxygenation for patients with refractory coronavirus disease 2019 (COVID-19): multicenter experience of referral hospitals in a large health care system. J Thorac Cardiovasc Surg. 2020. https://doi.org/10.1016/j.jtcvs.2020.11.073.
41. Japan ECMO network. 2021. Available on https://crisis.ecmonet.jp/. Accessed 10 Jan 2021.

42. Zayat R, Kalverkamp S, Grottke O, Durak K, Dreher M, Autschbach R, Marx G, Marx N, Spillner J, Kersten A. Role of extracorporeal membrane oxygenation in critically ill COVID-19 patients and predictors of mortality. Artif Organs. 2021;45(6):E158-E170.

43. Zhang J, Merrick B, Correa GL, Camporota L, Retter A, Doyle A, Glover GW, Sherren PB, Tricklebank SJ, Agarwal S et al. Veno-venous extracorporeal membrane oxygenation in coronavirus disease 2019: a case series. ERJ Open Res. 2020;6(4). https://doi.org/10.1183/23120541.00463-2020

44. Combes A, Hajage D, Capellier G, Demoule A, Lavoue S, Guervilly C, Da Silva D, Zafrani L, Tirot P, Veber B, et al. Extracorporeal membrane oxygenation for severe acute respiratory distress syndrome. N Engl J Med. 2018;378(21):1965-75.

45. Peek GJ, Mugford M, Tiruvoipati R, Wilson A, Allen E, Thalanany MM, Hibbert CL, Truesdale A, Clemens F, Cooper N, et al. Efficacy and economic assessment of conventional ventilatory support versus extracorporeal membrane oxygenation for severe adult respiratory failure (CESAR): a multicentre randomised controlled trial. Lancet. 2009;374(9698):1351-63.

46. Combes A, Peek GJ, Hajage D, Hardy P, Abrams D, Schmidt M, Dechartres A, Elbourne D. ECMO for severe ARDS: systematic review and individual patient data meta-analysis. Intensive Care Med. 2020;46(11):2048-57.

47. Yang X, Cai S, Luo Y, Zhu F, Hu M, Zhao Y, Zheng R, Li X, Hu B, Peng $Z$. Extracorporeal membrane oxygenation for coronavirus disease 2019-induced acute respiratory distress syndrome: a multicenter descriptive study. Crit Care Med. 2020;48(9):1289-95.

48. Posluszny J, Rycus PT, Bartlett RH, Engoren M, Haft JW, Lynch WR, Park PK, Raghavendran K, Napolitano LM, Centers EM. Outcome of adult respiratory failure patients receiving prolonged ( $>/=14$ Days) ECMO. Ann Surg 2016;263(3):573-81

49. Shintani AK, Girard TD, Eden SK, Arbogast PG, Moons KG, Ely EW. Immortal time bias in critical care research: application of time-varying Cox regression for observational cohort studies. Crit Care Med. 2009;37(11):2939-45.

50. Hsin CH, Wu MY, Huang CC, Kao KC, Lin PJ. Venovenous extracorporeal membrane oxygenation in adult respiratory failure: Scores for mortality prediction. Medicine (Baltimore). 2016;95(25):e3989.

51. Zhang J, Whebell SF, Sanderson B, Retter A, Daly K, Paul R, Barrett N, Agarwal S, Lams BE, Meadows C, et al. Phenotypes of severe COVID-19 ARDS receiving extracorporeal membrane oxygenation. $\mathrm{Br} J$ Anaesth. 2020;126:e130-2.

52. MacLaren G, Combes A, Brodie D. What's new in ECMO for COVID-19? Intensive Care Med. 2020:47:107-9.

\section{Publisher's Note}

Springer Nature remains neutral with regard to jurisdictional claims in published maps and institutional affiliations.

Ready to submit your research? Choose BMC and benefit from:

- fast, convenient online submission

- thorough peer review by experienced researchers in your field

- rapid publication on acceptance

- support for research data, including large and complex data types

- gold Open Access which fosters wider collaboration and increased citations

- maximum visibility for your research: over $100 \mathrm{M}$ website views per year

At BMC, research is always in progress.

Learn more biomedcentral.com/submissions 